\title{
Chemical Stability of Pharmaceutical Organic Compounds
}

\author{
Topwe Milongwe Mwene-Mbeja* \\ Department of Chemistry, University of Lubumbashi, Congo
}

*Corresponding author: Topwe Milongwe Mwene-Mbeja, Faculty of science, Department of Chemistry, University of Lubumbashi, Lubumbashi, Congo.

To Cite This Article: Topwe Milongwe Mwene-Mbeja . Chemical Stability of Pharmaceutical Organic Compounds. Am J Biomed Sci \& Res. 2019 6(1). AJBSR.MS.ID.000984. DOI: 10.34297/AJBSR.2019.06.000984.

Received: 眥 September 23, 2019; Published: 眥 October 30, 2019

\begin{abstract}
According to the reaction conditions, medicines or pharmaceutical organic compounds can be altered via hydrolysis or elimination reactions They can also degrade through isomerisation, oxidation or polymerization. This review aims to show the reaction mechanisms related to the stability of medicines. In that context, mechanisms are useful in order to explain the formation of products into the chemical reaction medium. When medicines are in an inadequate reaction medium, they disintegrate accordingly. Therefore, it is very important to understand the conditions which modify the stability of medicines so that to identify means to ensure their stability. Indeed, the chemical or physical degradation can alter the therapeutic efficiency of a medicine and it can lead to the production of undesirable products.
\end{abstract}

Keywords: Chemistry; Medicine; Degradation; Mechanisms

\section{Penicillin}

It has been reported that hydrolytic enzymes such as penicillin acylase, isolated from d'Echerichia coli, is able to catalyze the hydrolysis of natural penicillin to produce 6-aminopenicillanic acid. This acid is an important intermediate in the semi-synthetic preparation of antibiotics [1-7]. Experimental observations and structural studies of the enzyme showed that the serine hydroxyl group is transformed into an ester group (Scheme 1A) [1-7]. In other words, the serine hydroxyl group, in the enzyme active center, acts as a nucleophile and the enzyme is regenerated by the nucleophile attack on the serine acyl intermediate or acyl enzyme (Scheme 1B).

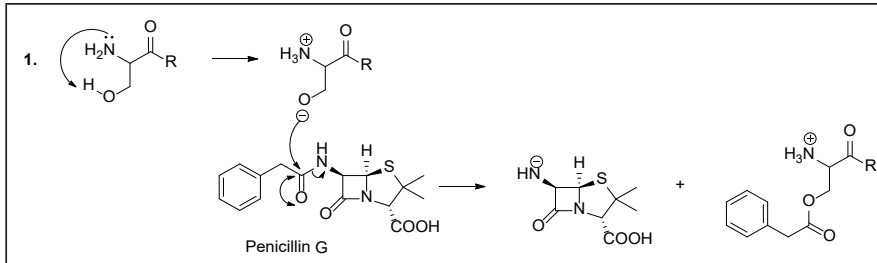

Scheme 1A
2.

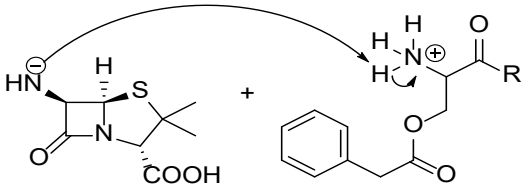<smiles>CC1(C)S[C@@H]2C(N)C(=O)N2C1C(=O)O</smiles>

6-Aminopenicillanic acid

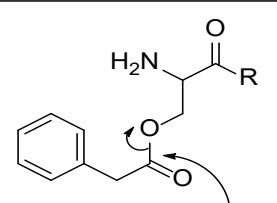

Acyl enzyme<smiles>C[Te]CO</smiles>

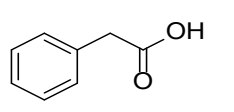

Regenerated enzyme 
It is known that penicillin is generally sensible to acid conditions which catalyze its destruction. The plausible mechanism to explain such decomposition would be due to the proximity of the secondary chain carbonyl group to that of the $\beta$-lactam ring. Indeed, the acid reacts with the nitrogen intra cyclic atom to break the amide bond. The breaking is rendered possible by the extra cyclic nitrogen atom, which donates its non-bonded electrons to the secondary chain carbonyl group, which in turn donates its electrons to the $\beta$-lactam ring to induce the formation of new ring and the breaking of the $\beta$-lactam ring, leading therefore to the complete destruction of the penicillin (Scheme 2, Reaction 1) [1-7]. It has also been observed that penicillinase is a $\beta$-lactamase enzyme which destroys penicillin by specifically catalyzing the hydrolysis reaction of $\beta$-lactam ring to produce penicillic acid (Scheme 2, Reaction 2) [8].

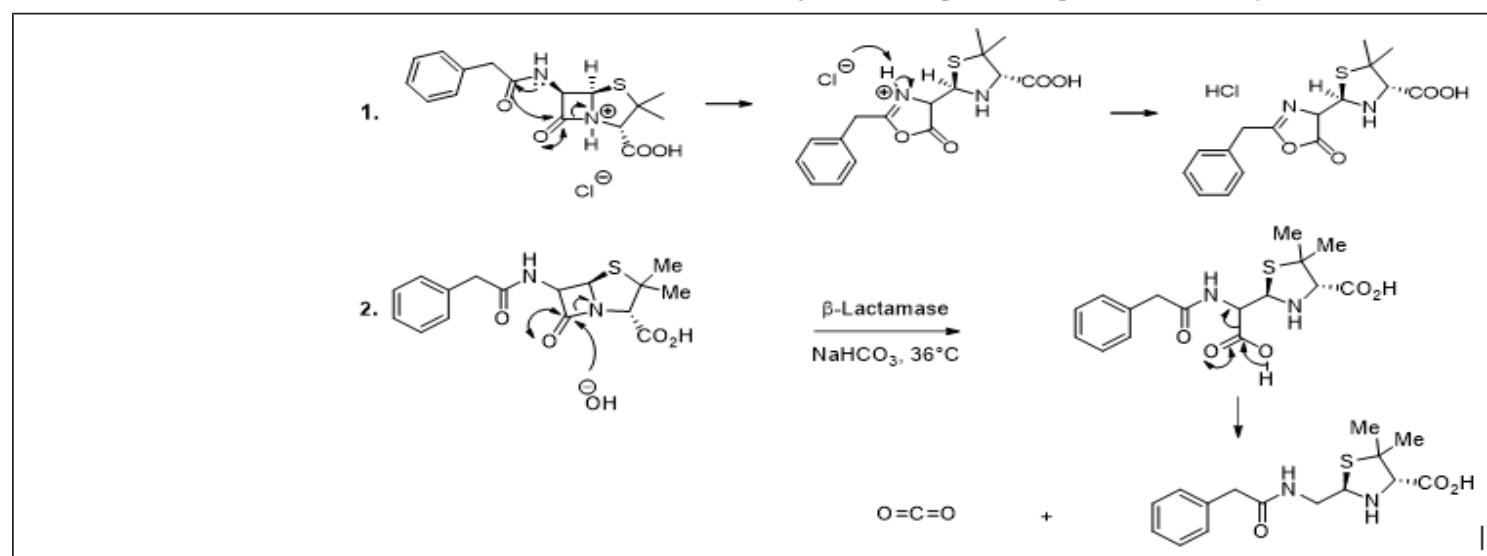

\section{Scheme 2}

The metallic ions such as zinc (II) and cadmium (II) are capable to assist the degradation of four classical penicillin as it happens to amoxicillin, ampicillin, penicillin $\mathrm{G}$ and penicillin $\mathrm{V}$ in the methanol. In that type of reaction, the Lewis acid activates the lactam ring carbonyl group, and enhances the electrophilic character of the carbon atom of the activated lactam ring carbonyl group, and methanol reacts as nucleophile (Scheme 3) [9].<smiles>COC(=O)C(NC(=O)Cc1ccccc1)C1N[C@@H](C(=O)O)C(C)(C)S1</smiles>

\section{Scheme 3}

\section{Carbapenem}

Carbapenems are $\beta$-lactam antibiotics possessing a very large activity against bacteria and a very high resistance to most $\beta$-lactam because of their chemical structures [1-41]. Therefore, they belong to the category of antibiotics used in the first line during severe nosocomial infections [10-50]. These kinds of antibiotics were developed from carbapenem thienamycin, a natural product derived from Streptomyces cattleya [10-50] Experimental observations showed that the structure of carbapenem decomposes by Hofmann degradation or nucleophilic substitution reaction $\left(\mathrm{S}_{\mathrm{N}} 2\right)$ (Scheme 4) [10-50].

\section{Atracurium}

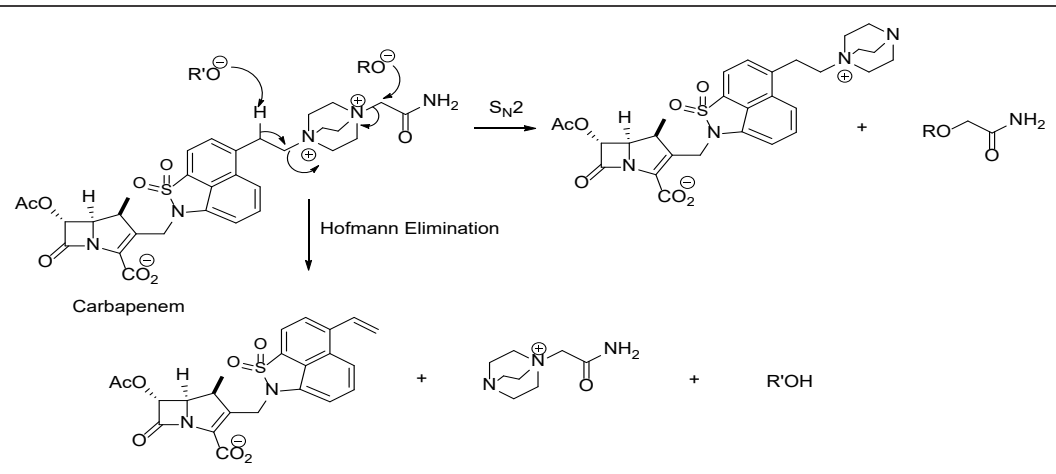

Scheme 4 
A medicine like atracurium is destroyed by several routes including the Hofmann elimination reaction. This later is a spontaneous degradation which occurs into the plasma and tissues at the human body's normal temperature and $\mathrm{pH}$ [10-50]. In this regard, the inhibition of neuromuscular transmission by atracurium is caused by the presence of quaternary nitrogen located at each of the congested ends, which are linked by an aliphatic chain. The structure of atracurium shows two ester groups and an asymmetric centre in each terminal end. The Hofmann elimination reaction commonly known as Hofmann degradation takes place thanks to the presence of two ester groups. Such a reaction was observed at the two ends of atracurium (Scheme 5) [10-50].

\section{Duloxetine}

Duloxetine is a solid organic substance slightly soluble into water. This medicine is used to treat the depression and generalized anxiety disorder. It can be used to relieve urinary incontinence. The stability of this medicine depends on the storage conditions, chemical properties, and its impurities. In that perspective, experimental observation showed the disintegration of duloxetine, under alkaline conditions, to corresponding products as naphthol [51]. The plausible mechanism to explain the disintegration products involves the electronic doublet of the duloxetine oxygen atom. In other words, the delocalisation of the electronic doublet of the oxygen atom leads to the generation of two forms of resonance. The action of the base upon the ionic intermediate compound facilitates the disintegration of the medicine and a water molecule permits the formation of naphthol (Scheme 6, reaction 2). On the other hand, it has been observed that under acidic conditions, the degradation product is not naphthol (Scheme 6, reaction 5) [51].
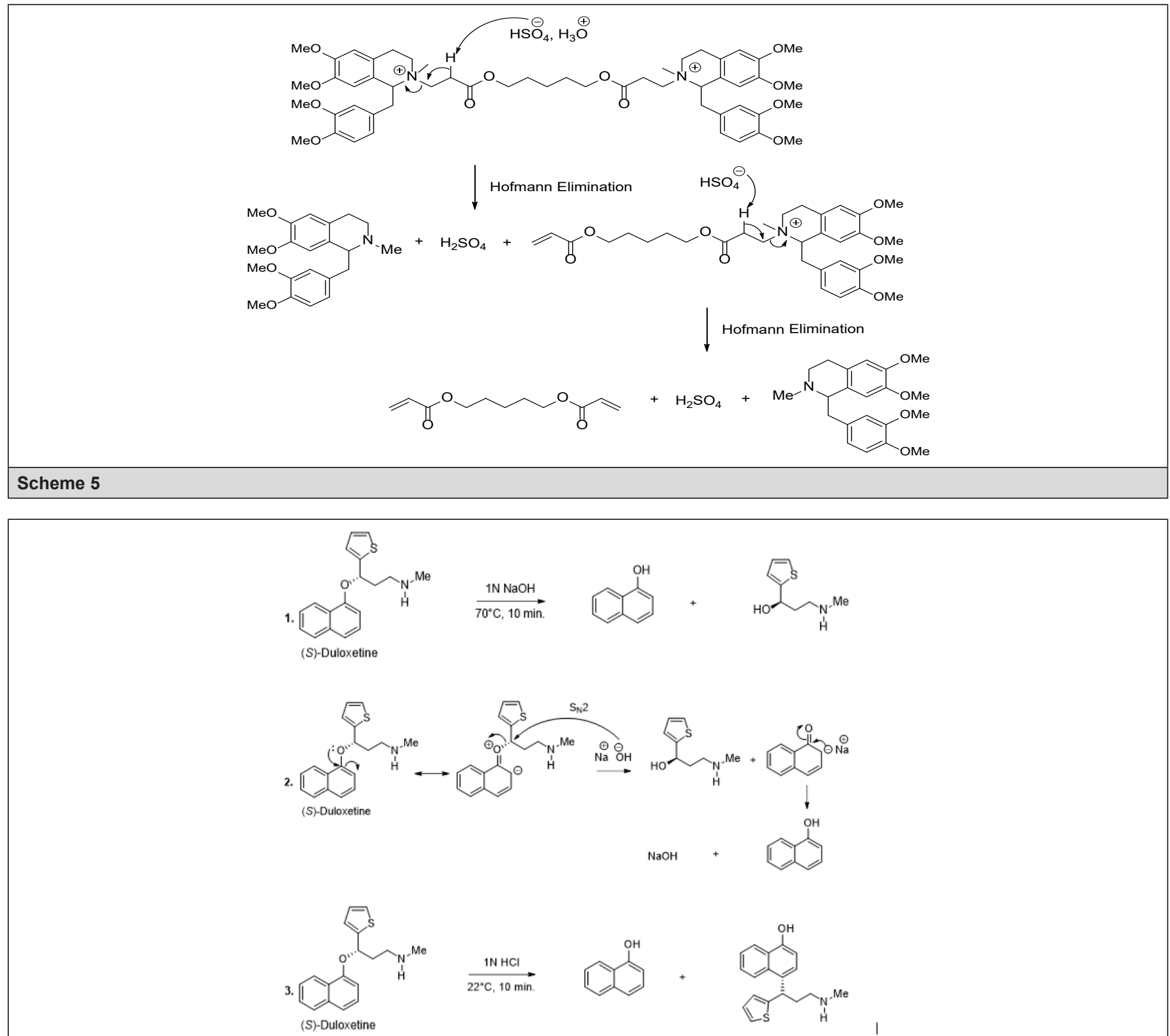

Scheme 6A 


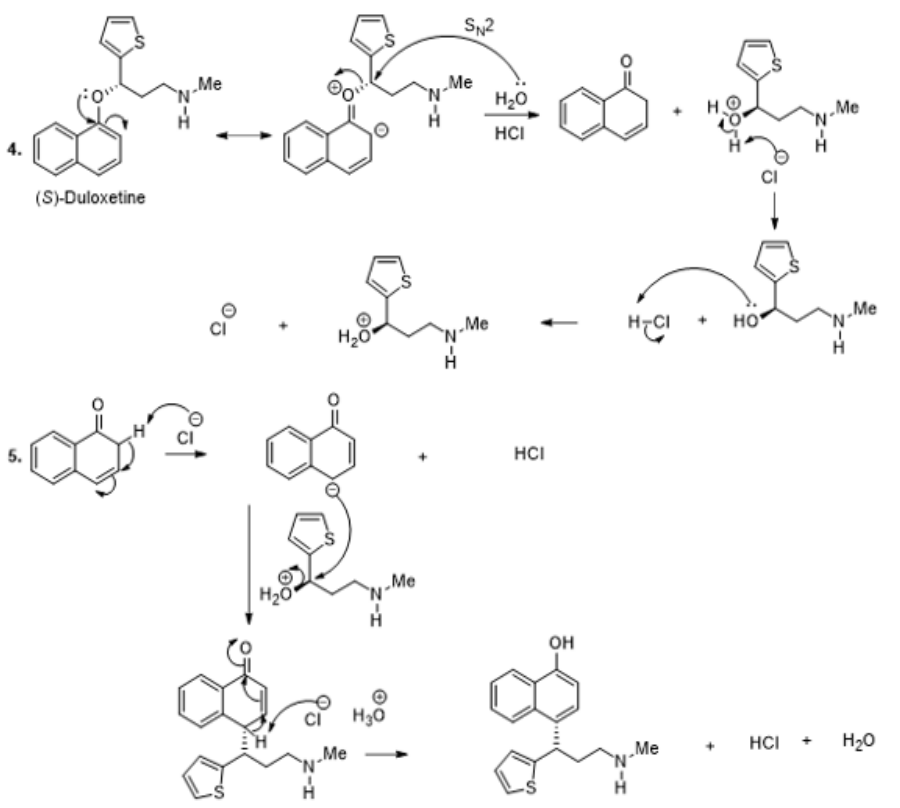

\section{Scheme 6B}

\section{Bosentan}

Bosetan is a medicine used to treat pulmonary hypertension, chronic heart weakness and Raynauld syndrome. 56 It is one of the latest cardiovascular medicines [52-54]. The experimental observations showed that bosentan is sensible to acidic and alkaline conditions, and the degradation products are the same in acidic or alkaline environment [56]. In this context, the proposed reaction mechanism, in alkaline medium, involves the removal of the acidic proton from the primary alcohol by the base. This alkali action facilitates the elimination of the leaving group due to the nucleophilic attack by the resulting alcoholate ion. Therefore, the hydroxyl group attached to the aryl ring and the epoxide was formed into the medium reaction (Scheme 7, reaction 2).

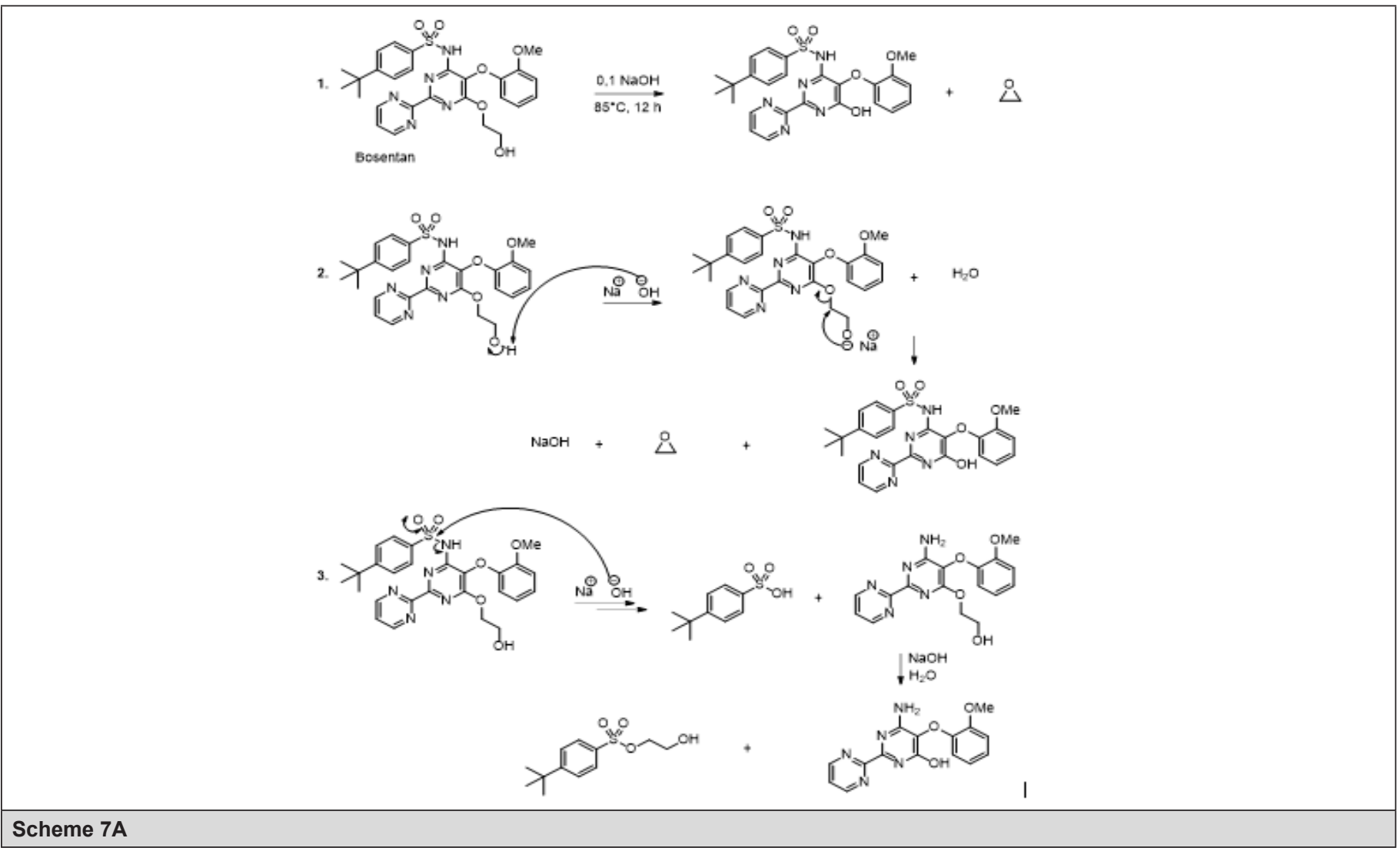



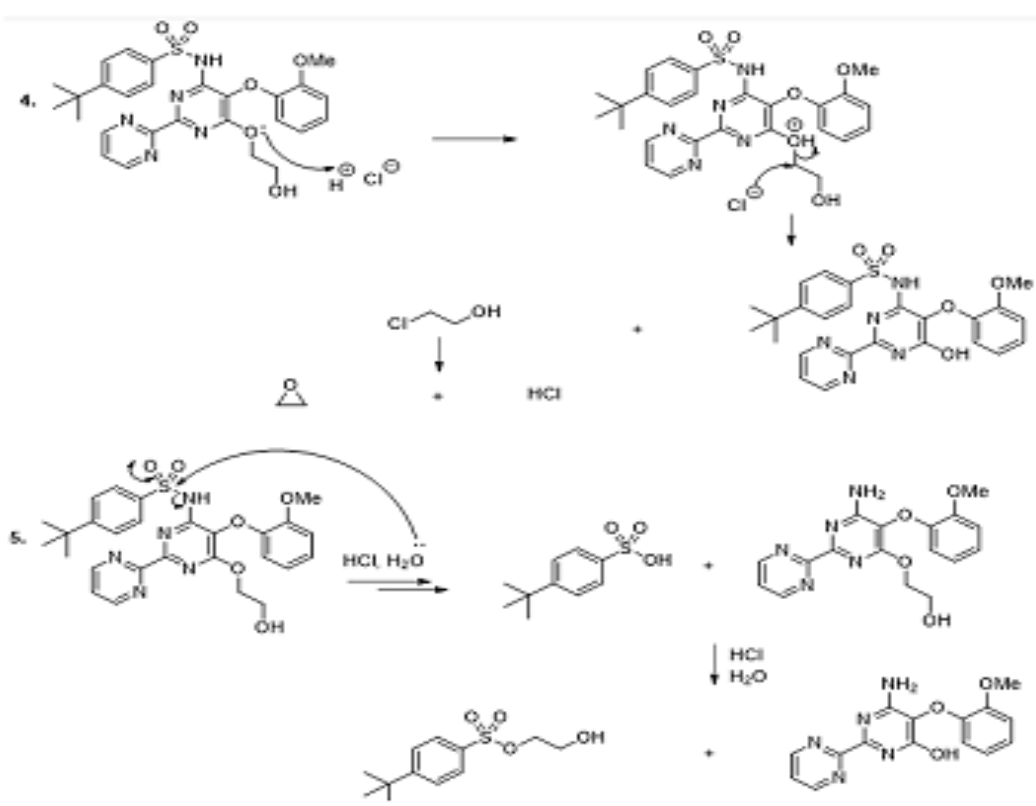

\section{Scheme 7B}

In the acidic conditions however, the hydrolysis begins by the protonation of the ether oxygen. This step is followed by the chloride ion nucleophilic attack to generate phenol and 2-chloroethanol. The latter can spontaneously cyclize to produce the epoxide and hydrochloric acid (Scheme 7 , reaction 3). The amide bond was also hydrolyzed in alkaline medium as well as in acidic environment (Scheme 7, reaction 3). The authors observed

\section{Candesartan cilexetil}

also that the oxidation of bosentan by hydrogen peroxide (30\%) took place for 24 hours at the room temperature, and it produced identical compounds as in the case of hydrolysis conditions. This kind of chemical behavior of bosentan was explained by the acidic character of hydrogen peroxide (Schema 7). It was observed that this medicine is stable in water [56].

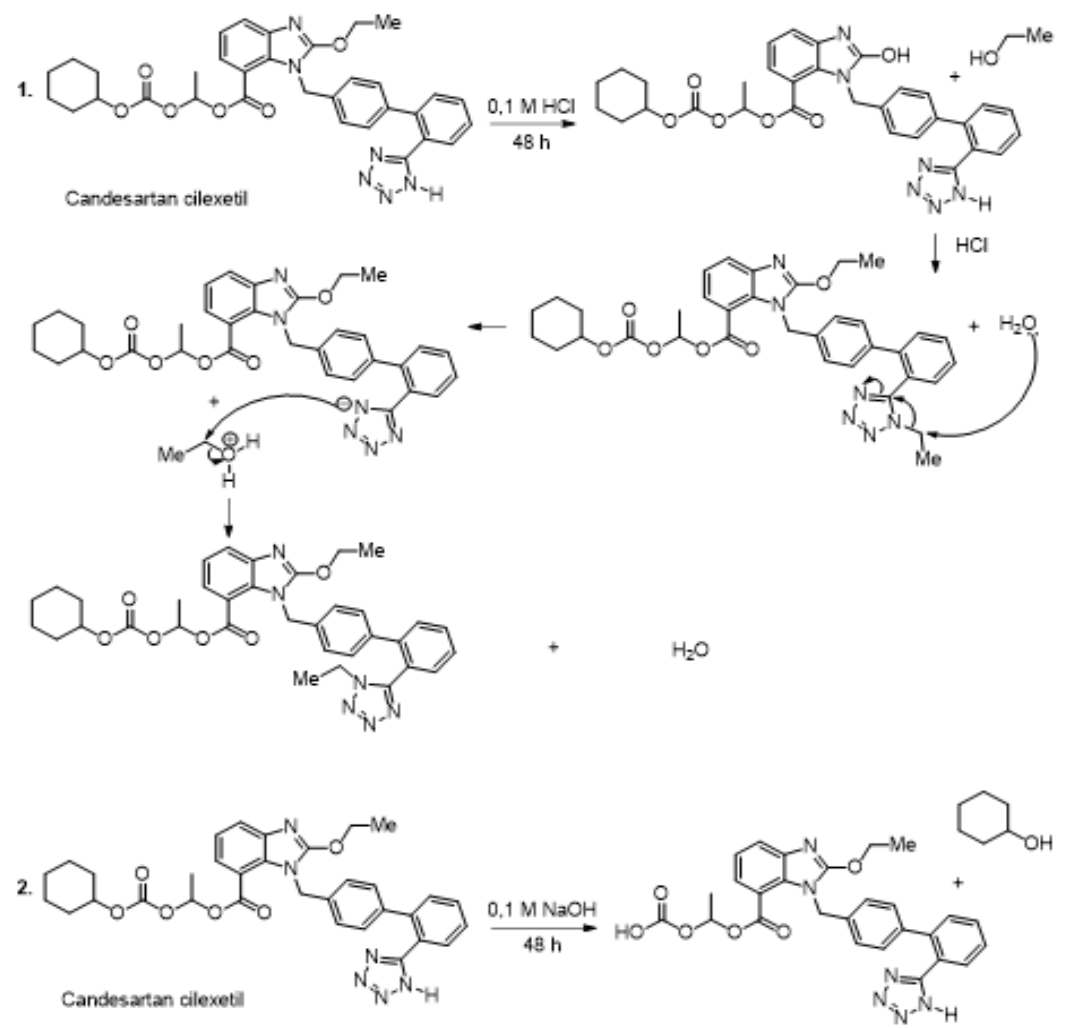


The candesartan cilexetil is a medicine utilised to treat high blood pressure. It reacts with the angiotensin II receptors or proteins, and by doing so it blocks the ability of the angiotensin II, which increases the blood pressure in the arteries. This medicine is not stable in the hydrolysis as well as in oxidation conditions. Indeed, the experimental observations showed that, during 48 hours, the medicine was decomposed and the authors observed

\section{Voriconazole}

identical degradation products in the aqueous acidic medium $(0,1 \mathrm{M} \mathrm{HCl})$, aqueous medium ( $\mathrm{H} 2 \mathrm{O})$, and the presence of hydrogen peroxide $(0,10 \% \mathrm{H} 2 \mathrm{O} 2)$ (Scheme 8, reaction 1). In contrary, the alkaline conditions $(0,1 \mathrm{M} \mathrm{NaOH})$, for 48 hours, generated one impurity because the ester group was removed (Scheme 8, reaction 2) [57].

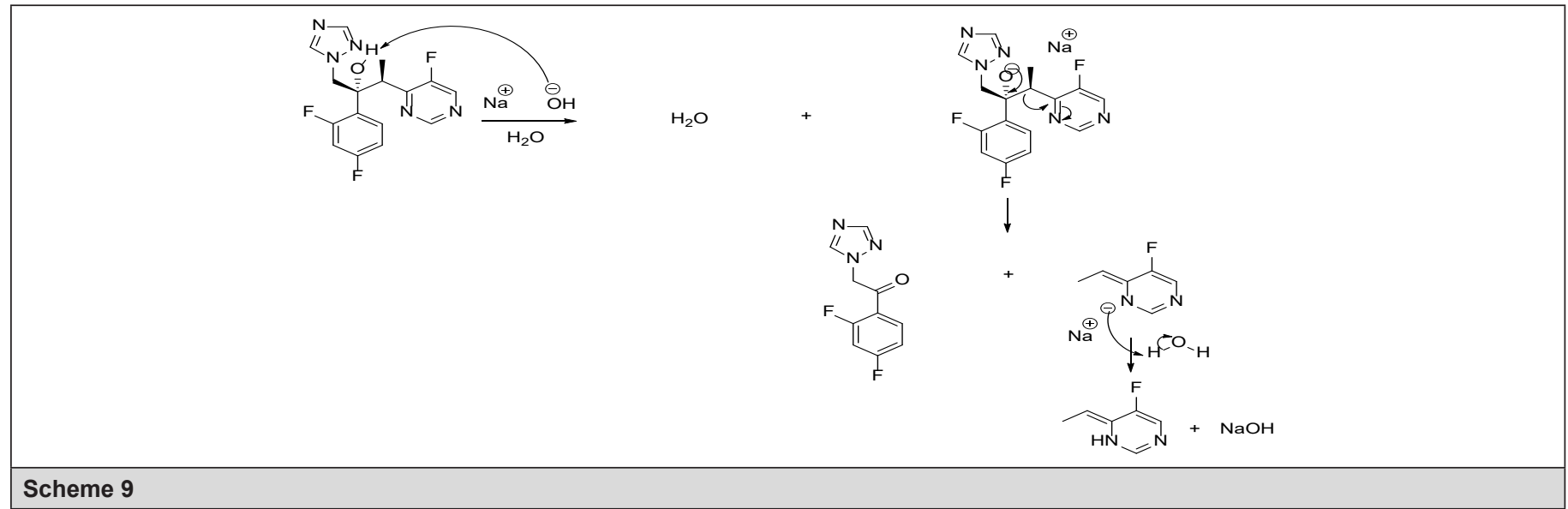

Voriconazole is a broad-spectrum fungicidal medicine. The study on the chemical stability showed that voriconazole is relatively stable in the solid form but instable when it is dissolved in alkaline medium or in the presence of an oxidant. The formation of the degradation products involves the removal of the tertiary alcohol proton by the base to produce an ionic adduct. The latter decomposes to generate the corresponding ketone and ionic aryl alkene. The action of a molecule of water upon the aryl anion alkene promotes the formation aryl alkene, and the regeneration of sodium hydroxyl (Scheme 9) [58].

\section{Paracetamol}

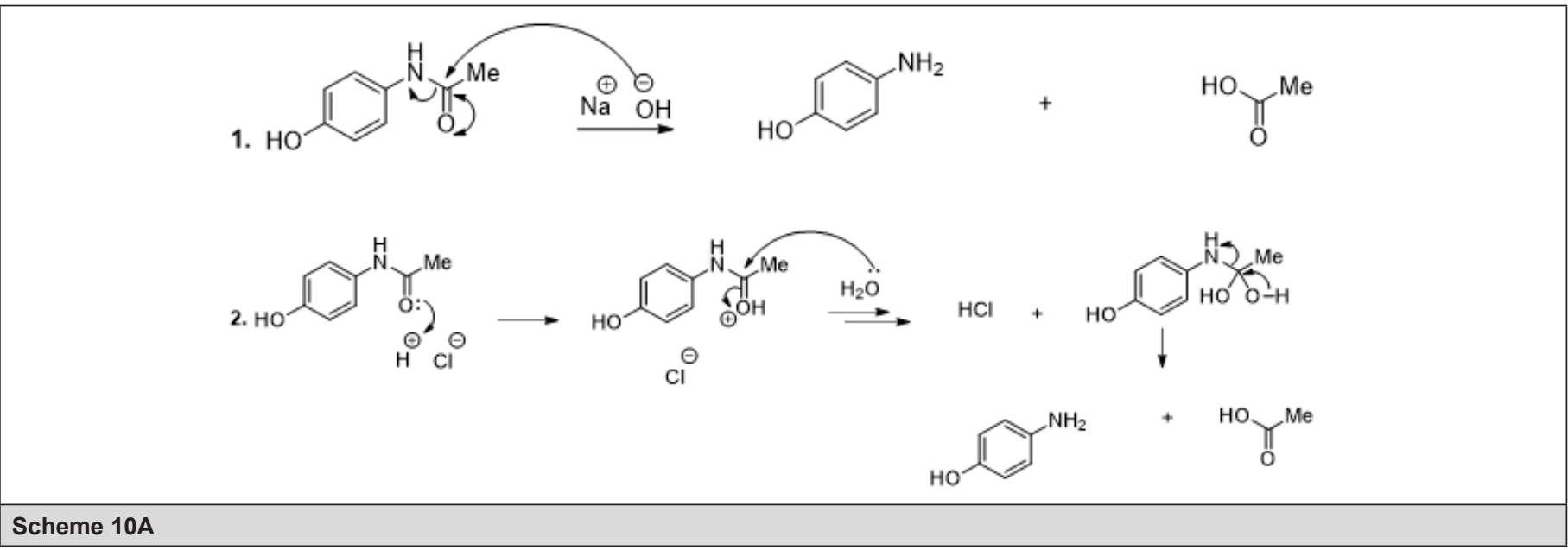

Scheme 10A

3. $\mathrm{H}$<smiles>CCCCC[NH+](C(C)=O)c1ccc(O)cc1</smiles><smiles>CC(=O)Nc1ccc(O)cc1</smiles><smiles>CC(=O)N=C1C=CC(=O)C=C1</smiles> 
Therapeutically, paracetamol is a medicine utilised to relieve pain and inflammations.59 In this perspective, it is usually used to relieve headaches and it is incorporated as main ingredient into various flu medications. The disintegration study revealed that paracetamol decomposes substantially under alkaline conditions (Schema 10, reaction 1), acidic (Scheme 10, reaction 2), and in the presence of hydrogen peroxide (Schema 10, reaction 3) [59].

\section{Pipenzolate bromide}

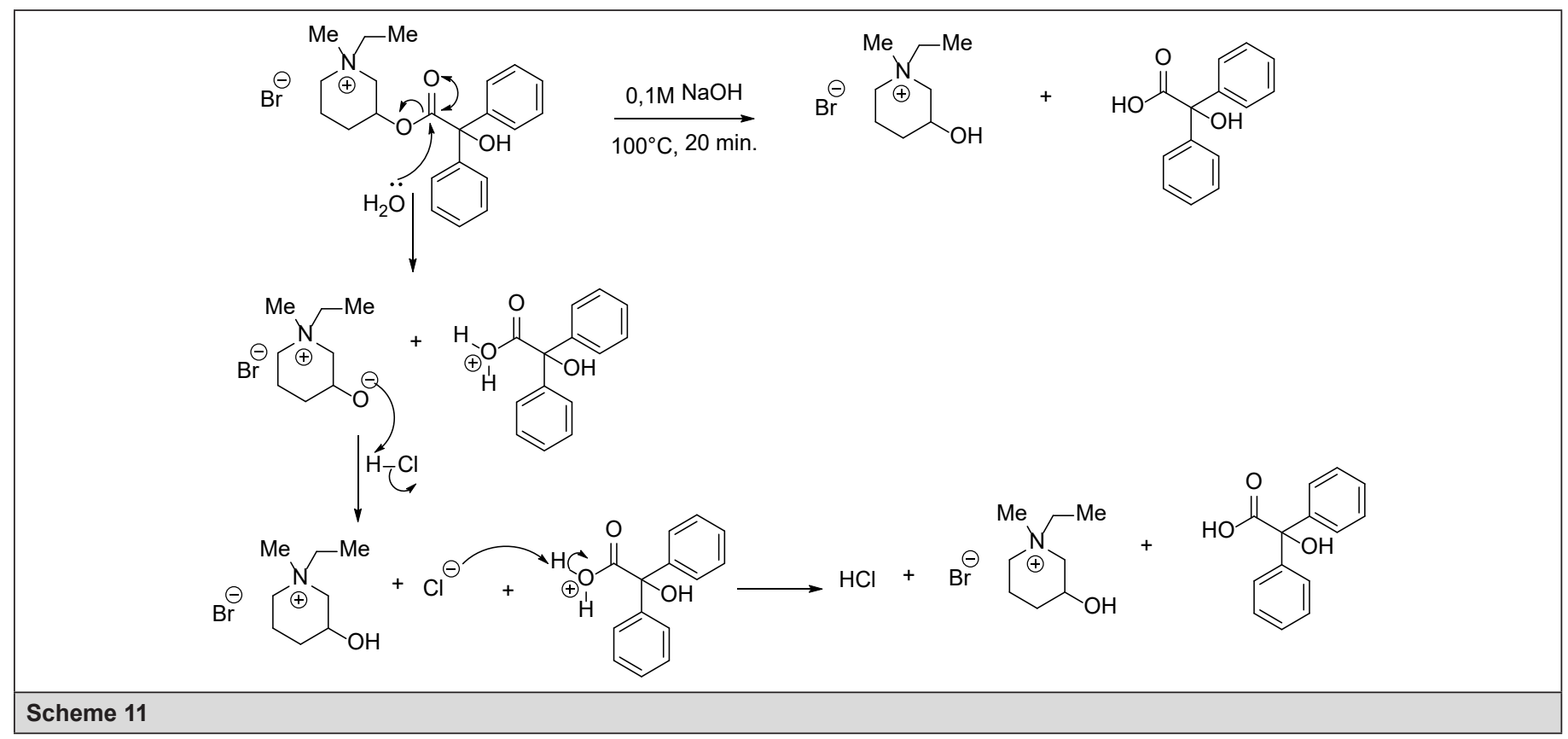

Pipenzolate bromide is an organic substance with a quaternary ammonium center. From medical point of view, pipenzolate bromide is an anti-muscarinic medicine useful in the treatment of overactive bladder. The chemical structure shows that pipenzolate bromide is an ester typical medicine. Consequently, it is sensible to the hydrolysis catalyzed by an acid or base, and the fragmentation products are identical in the acidic hydrolysis or base hydrolysis (Scheme 11) [60].

\section{Aspirin}

Aspirin is a medicine used as an analgesic, against inflammation, and as antipyretic. It is also used to prevent cardiovascular diseases. Structurally speaking, aspirin is an organic compound containing an ester group. That is why, it is sensible to hydrolysis and oxidation conditions. It has been observed that when aspirin is dissolved in aqueous solution containing $0,1 \mathrm{~N} \mathrm{HCl}$ or $0,1 \mathrm{~N} \mathrm{NaOH}$, it decomposes to corresponding acids (Scheme 12).<smiles>CC(=O)Oc1ccccc1C(=O)O</smiles>

Acetyl salicylic acid (Asprin)

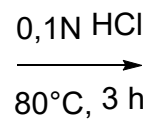<smiles>CC(=O)O</smiles>

$\mathrm{OH}$ C, $3 \mathrm{~h}$<smiles>CC(=O)O</smiles>

$+$<smiles>O=C(Oc1ccccc1C(=O)O)c1ccccc1O</smiles>

Acetic acid<smiles>O=C(O)c1ccccc1O</smiles>

Salicylic acid<smiles>CC(=O)Oc1ccccc1C(=O)O</smiles>

O Acetyl group hydrolysis<smiles>CC(=O)Oc1ccccc1C(=O)Oc1ccccc1C(=O)O</smiles>

Acetyl salicyl salicylic acid 


\section{Conclusion}

We have illustrated the chemical stability of pharmaceutical organic compounds using hydrolysis, elimination and oxidation reactions. We also proposed plausible mechanisms, as an interesting means, to demonstrate the formation of their degradation products. It is very important to mention that the decomposition of pharmaceutical organic compounds depends on the strength of an acid or a base. In other words, strong acids or bases are well indicated to study the disintegration of medicines.

\section{Conflict of Interest Statement}

I declare that I do not have a conflict of interest regarding the publication of this paper.

\section{References}

1. Hofmann AF, Hagey LR, Krasowski MD (2010) Bile salts of vertebrates: structural variation and possible evolutionary significance. J Lipid Res 51(2): 226-246.

2. Chilov GG, Sidorova AV, Dvedas VK (2007) Quantum chemical studies of the catalytic mechanism of N-terminal nucleophile hydrolase. Biochemistry (Moscow) 72(5): 495-500.

3. Favre A, Grugier J, Brans A, Joris B, Marchand Brynaert J (2012) 6-Aminopenicillanic acid (6-APA) derivatives equipped with anchoring arms. Tetrahedron 68(52): 10818-10826.

4. Baptissart M, Vega A, Maqdasy S, Caira F, Baron S, et al. (2013) Bile acids: from digestion to cancers. Biochimie 2013, 95(3): 504-517.

5. Griffiths WJ, Sjövall S (2010) Bile acids: analysis in biological fluids and tissues. J Lipid Res 51(1): 23-41.

6. Hofmann AF, Hagey LR, Krasowski MD (2010) Bile salts of vertebrates structural variation and possible evolutionary significance. J Lipid Res 51(2): 226-246.

7. Mukhopadhyay S, Maitra U (2004) Chemistry and biology of bile acids Curr Sci 87(12): 1666-1683.

8. Volpato G, Rodrigues RC, Fernandez Lafuente R (2010) Use of enzymes in the production of semi-synthetic penicillins and cephalosporins: drawbacks and perspectives. Curr Med Chem 17(32): 3855-3873.

9. Kovacs Hadady K, Kiss IT, Kiss M, Barna Katona K (1988) Determination of p-hydroxy phenoxymethylpenicillin in phenoxymethylpenicillin by derivative spectrophotometry Analyst 113(4): 569.

10. Richmond MH, Sykes RB (1973) The beta-lactamases of gram-negative bacteria and their possible physiological role. Adv Microbiol Phys 9: 31 38.

11. Navarro PG, Blázquez IH, Osso BQ Martínez de las Parras PJ, Puentedura MI, et al. (2003) Penicillin degradation catalysed by Zn (II) ions in methanol. Int J Biol Macromol 33(4-5): 159-166.

12. Van Benschoten JE, Edzwald JK (1990) Chemical aspects of coagulation using aluminum salts-I. Hydrolytic reactions of alum and polyaluminum chloride Water Res 24(12): 1519-1526.

13. Goodman C (2014) Carbohydrates: Cutting out starch. Proc Natl Acad Sci USA 111: 13822

14. Soto D, Urdaneta J, Pernia K (2014) Characterization of native and modified starches by potentiometric titration. Journal of Applied Chemistry.

15. Hayek M, Shriner RL (1944) Hydrolysis of Starch by Sulfurous Acid. Ind Eng Chem 36(11): 1001-1003.

16. Oates CG (1997) Towards an understanding of starch granule structure and hydrolysis. Trends Food Sci Technol 8(11): 375-382.
17. Ring SG, Gee JM, Whittam M, Orford P, Johnson IT (1988) Resistant starch: Its chemical form in foodstuffs and effect on digestibility in vitro. Food Chem 28(2): 97-109.

18. Savage PE (1999) Organic Chemical Reactions in Supercritical Water Chem Rev 99(2): 603-622.

19. Abdul Rahman MB, Krishnan D, Jelas Haron MD, Tejo BA, Abdulmalek E, et al. (2013) Lipase-Catalyzed Amino Sugar Derivative in Tri-solvent Mixture. Asian J Chem 25(6): 3015

20. Boehm MF, Bada JL (1984) Racemization of aspartic acid and phenylalanine in the sweetener aspartame at 100 degrees C. Proc Natl Acad Sci USA 81(16): 5263-5266.

21. Oyama K, Kihara K, Nonaka Y (1981) On the mechanism of the action of thermolysin: kinetic study of the thermolysin-catalysed condensation reaction of N-benzyloxycarbonyl-L-aspartic acid with L-phenylalanine methyl ester. J Chem Soc Perkin Trans 356.

22. Hooper NM, Hesp RJ, Tieku S, Boesten WHJ, Toniolo C, et al. (1994) Stability of N-Derivatized and. alpha. -Methyl Analogs of Aspartame to Hydrolysis by Mammalian Cell-Surface Peptidases. J Agric Food Chem 42(7): 1397-1401.

23. Krol WJ, Mao S, Steele DL, Townsend CA (1991) Stereochemical correlation of proclavaminic acid and syntheses of erythro- and threo-Lbeta. -hydroxyornithine from an improved vinylglycine synthon. J Org Chem 56(2): 728-731.

24. José M Macarulla, Miguel Trueba, Alberto Macarulla (1994) Assay differentiation between enantiomeric isomers of chiral molecules without asymmetric carbons: A simplified system. Biochem Ed pp. 22 25.

25. Gill M, Morgan PM (2004) Absolute stereochemistry of fungal metabolites: icterinoidins A1 and B1, and atrovirins B1 and B2 ARKIVOC p.152-165.

26. Cahn RS, Ingold C, Prelog V (1966) Specification of Molecular Chirality. Angew Chem Int Ed Engl 5: 385.

27. Jing Q, Kazlauskas RJ (2008) Determination of absolute configuration of secondary alcohols using lipase-catalyzed kinetic resolutions. Chirality 20(5): 724-735

28. Davis SC, Severson SJ, Klabunde KJ (1981) Clustering of Metal Atoms in Organic Media. 8. Low Temperature Cleavage of Alkanes by Small Nickel Particles Resulting in Stable Nickel Organic Composities with Unusual Magnetic and Chemical Properties J. Am. Chem. Soc. 1981, 103, 3024

29. Sugiura K, Ishihara M, Shimauchi T, Harayama S (1997) Physicochemical Properties and Biodegradability of Crude Oil. Environ Sci Technol 31(1): 45-51.

30. Boese R, Weiss HC, Blaser D (1999) The Melting Point Alternation in the Short-Chain n-Alkanes: Single-Crystal X-Ray Analyses of Propane at $30 \mathrm{~K}$ and of n-Butane to n-Nonane at $90 \mathrm{~K}$. Angew Chem Int Ed 38: 988.

31. Mumma MJ, Disanti MA, dello Russo N, Fomenkova M, Magee Sauer K, et al. (1996) Science 272(5266): 1310-1314.

32. Akiya N, Savage PE (2002) Roles of Water for Chemical Reactions in High-Temperature Water. Chem Rev 102(8): 2725-2750.

33. Davidson JM, Linforth RST, Hollowood TA, Taylor AJ (1999) Effect of Sucrose on the Perceived Flavor Intensity of Chewing Gum J Agric Food Chem 47(10): 4336-4340.

34. Klostergaard H (1976) Inversion of sucrose and fructose structure. J Chem Educ 53(5): 298.

35. Dordick RS, Clarke GA (1979) Salt Effects on the Hydrolysis of Sucrose. J Chem Educ 56: 352

36. Toufeili IA, Dziedzic SZ, Rathbone EB (1986) C-methylation of sucrose: synthesis of 6- and 6'-C-methylsucrose Carbohyd Res 148(2): 279-285.

37. Kehlbeck JD, Slack CC, Turnbull MT, Kohler SJ (2014) Exploring the Hydrolysis of Sucrose by Invertase Using Nuclear Magnetic Resonance 
Spectroscopy: A Flexible Package of Kinetic Experiments. J Chem Educ 91(5): 734-738.

38. Heinzerling P, Schrader F, Schanze S (2012) Measurement of Enzyme Kinetics by Use of a Blood Glucometer: Hydrolysis of Sucrose and Lactose. J Chem Educ 89(12): 1582-1586.

39. Abdel Magid AF, Carson KG, Harris BD, Maryanoff CA, Shah RD (1996) Reductive Amination of Aldehydes and Ketones with Sodium Triacetoxyborohydride. Studies on Direct and Indirect Reductive Amination Procedures (1). J Org Chem 61(11): 3849-3862.

40. Taibakhsh M, Hosseinzadeh R, Alinezhad H, Ghahari S, Heydari A (2011) Catalyst-Free One-Pot Reductive Alkylation of Primary and Secondary Amines and N, N-Dimethylation of Amino Acids Using Sodium Borohydride in 2,2,2-Trifluoroethanol. Synthesis 2011(3): 490-496.

41. Dangerfield EM, Plunkett CH, Win Mason AL, Stocker BL, Timmer MSM (2010) Protecting-Group-Free Synthesis of Amines: Synthesis of Primary Amines from Aldehydes via Reductive Amination. J Org Chem 75(16): 5470-5477.

42. Salvatore RN, Yoon CH, Jung KW (2001) Synthesis of secondary amines. Tetrahedron 57(37): 7785-7811.

43. Fisher DM, Canfell PC, Fahey MR, Rosen JI, Rupp SM, et al. (1986) Elimination of atracurium in humans: contribution of Hofmann elimination and ester hydrolysis versus organ-based elimination. Anesthesiology 65(1): 6-12.

44. Grobelny P, Mukherjee A, Desiraju GR (2012) Drug-drug co-crystals: Temperature-dependent proton mobility in the molecular complex of isoniazid with 4-aminosalicylic acid. Int Bull Drug Res 1: 24.

45. Savage PE (2000) Heterogeneous catalysis in supercritical water Catalysis Today 62(2-3): 167-173.

46. Liu TY, Chang WH (1971) Hydrolysis of proteins with p-toluenesulfonic acid. Determination of tryptophan. J Biol Chem 246(9): 2842-2848.

47. Zumwalt RW, Absheer JS, Kaiser FE, Gehrke CW (1987) Acid hydrolysis of proteins for chromatographic analysis of amino acids. J Assoc Off Anal Chem 70(1): 147-151.

48. Weindlmayer Goettel M, Kress HG, Hammerschmidt F, Nigrovic V (1998) In vitro degradation of atracurium and cisatracurium at $\mathrm{pH} 7.4$ and 37 degrees $\mathrm{C}$ depends on the composition of the incubating solutions. British J Anesthesiology 81(3): 409-414.
49. Wolff M, Joly Guillou ML, Pajot 0 (2008) Le point sur les carabapénèmes Comparative review of carbapenems. Réanimation 17(3): 242-250.

50. Livermore DM, Woodford N (2009) Carbapenemases: a problem in waiting. Curr Opinion Microbiol 3(5): 489-495.

51. Birnbaum J, Kahan FM, Kropp H, MacDonald JS (1985) Carbapenems, a new class of beta-lactam antibiotics. Discovery and development of imipenem/cilastatin. Am J Med 78(6A): 3-21.

52.Zhao ZZ, Qin XZ, Reed RA (2002) Identification by LC/MS(n) of degradates of a novel carbapenem antibiotic in an aqueous matrix. J Pharm Biomed Anal 29(1-2): 173-181.

53. Chakraborty S, Gruber T, Barry CE, Boshoff HI, Rhee KY (2013) Paraaminosalicylic acid acts as an alternative substrate of folate metabolism in Mycobacterium tuberculosis. Science 339(6115): 88-91.

54. Reddy PRM, Sreeramulu J, Naidu PY, Reddy AR (2010) Stability Indicating Fast LC for the Simultaneous Estimation of Intermediates and Degradants of Duloxetine Hydrochloride. Chromatographia 71(1-2): 95100.

55. Bansal G, Singh R, Saini B, Bansal Y (2013) ESI-MSn and LC-ESI-MS studies to characterize forced degradation products of bosentan and a validated stability-indicating LC-UV method. J Pharm Biomed Anal 72:186-197.

56. Rao DVS, Radhakrishnanand P, Suryanarayana MV, Himabindu V (2007) A Stability-Indicating LC Method for Candesartan Cilexetil. Chromatographia 66(7-8): 499-507.

57. Adams AIH, Gosmann G, Schneider PH, Bergold AM (2009) LC Stability Studies of Voriconazole and Structural Elucidation of Its Major Degradation Product. Chromatographia Suppl 69: 115-122.

58. Bhimavarapu R, Chitra KP, Meda H, Kanikanti D, Anne M, et al. (2011) FORCED DEGRADATION STUDY OF PARACETAMOL IN

TABLET FORMULATION USING RP-HPLC. Bull Pharm Res 1(3): 13-17.

59. Hadad GM (2008) Stability-indicating LC method for analysis of pipenzolate bromide and its hydrolysis products. Chromatographia 68(2008): 207-212.

60. Sherikar O, Mehta P (2013) Comprehensive Assessment of Degradation Behavior of Aspirin and Atorvastatin Singly and in Combination by Using a Validated RP-HPLC Method. Sci Pharm 81(1): 195-210. 